\title{
Understanding the SARS-CoV-2 virus to mitigate current and future pandemic(s)
}

\author{
Swaraj Mohanty ${ }^{1}$ (D) Subhojit Paul ${ }^{1}$ (D) Yasmin Ahmad $^{1}$ (D)
}

Received: 27 January 2021/ Accepted: 20 May 2021/Published online: 5 June 2021

(C) Indian Virological Society 2021

\begin{abstract}
Micro-organisms form the first pioneer community in the history of biological life, thought to be present in the primordial soup and evolving later with more complex life-forms. Among micro-organisms, viruses form a separate taxon of organisms. Viruses are obligate parasites, being inactive without a host and becoming active once in contact with specific hosts. Viruses, with an inherent ability to infect and hijack cellular structures, have been utilised as vectors to introduce foreign genetic material in a variety of biological species, e.g. adenoviral vectors. However, viruses have also been the root cause of many infectious diseases, most notable being HIV-AIDS, for its resistance to treatment and omnipresent occurrence. There are many families of viruses like retroviridae, picornaviridae and poxviridae. This review focuses on a specific member of the coronaviridae, the SARS-CoV-2. This virus is responsible for the current COVID-19 pandemic. This review summarises its transmission, molecular mechanism by which it causes disease, associated clinical symptoms and the strategies available to control it from sources like PubMed, Google Scholar, webservers of National Institute of Health (NIH), European Molecular Biology Laboratory (EMBL), World Health Organisation (WHO), United States Food and Drug Administration (USFDA) and Centers for Disease Control and Prevention (CDC) available as on 1st May 2021.
\end{abstract}

Yasmin Ahmad

yasminchem@gmail.com

1 Peptide and Proteomics Division, Defence Institute of Physiology and Allied Sciences (DIPAS), Defence R\&D Organization (DRDO), Lucknow Road, Timarpur, Delhi 110054, India
Keywords COVID-19 - SARS-CoV-2 - Cytokine storm · Molecular biology $\cdot$ HAPE

\section{Introduction}

A virus can be described as an obligate parasite which consists of a protein coat enclosing genetic material and is visualized only using electron microscopy. Their existence was first indicated by experiments trying to establish tobacco mosaic disease as an infectious disease while their visualization occurred much later in 1931 by the Nobel laureate W.M. Stanley with the advent of the electron microscope. One of the earliest experiments suspecting the presence of viruses was conducted by Ernest Hanbury Hankin in 1836 on $V$. cholera killing factor in the water obtained from Ganges. Later on, Felix Hubert d'Herelle and Frederick Twort separately visualized plaques in bacterial colonies with d'Herelle coining the term "bacteriophage" [1]. Simultaneous and later investigations revealed viruses to infect various other organisms, from plants to humans. In fact, multiple human diseases were traced to viral infections, including influenza, polio, hepatitis, AIDS, etc. However, viruses' ability to hijack the cell and modulate cellular replication, transcription and translation have been used widely in biological research [2]. The first virus identified as an infectious agent in humans was the yellow fever virus in 1901. Till 2012, about 200 viruses were known to infect humans, with multiple viruses capable of crossing the species barrier from other mammals and birds due to phylogenetically conserved cell receptors with potential to cause epidemics [3]. Viruses form the smallest and yet inalienable part of this planet's biosphere, extending right into our gut microbiota with immense implications on our health [4]. The International 
Committee on Taxonomy of viruses (ICTV) has created taxonomic framework for identification of myriad viruses with different tiers ranging from Realm and sub-realm to species at the bottom. As per ICTV in 2013, "A species is a monophyletic group of viruses whose properties can be distinguished from those of other species by multiple criteria" [5]. As is evident by the recent spate of events since December 2019, we are in the midst of a pandemic caused by a member of the Coronaviridae family. Based on the genome sequence deposited to the GenBank and Global initiative on sharing all influenza data (GISAID) researchers were able to create an open source global platform for the epidemiological study on the pathogenesis. Belonging to the order Nidovirales, these viruses have enveloped + ve ssRNA with genome sizes varying from 26 to $32 \mathrm{kB}$. The surface characteristic unique to this family is the presence of peplomers which are club/petalshaped and $\sim 20 \mathrm{~nm}$ in size giving these particles a unique "solar corona" like projection when visualized. They are reported to infect different animal groups including mammals $[6,7]$.

In late 2019, first evidence of a novel pneumonia like illness was uncovered in Wuhan, China and within January 2020, a public health emergency of international concern was declared by WHO affecting both general population and frontline healthcare responders [8-10]. The Chinese virologists identified a novel virus which was causing the flu like symptoms [11] and it was named novel Coronavirus (nCov) on 12th January 2020 by WHO. The severe acute respiratory syndrome coronavirus 2 (SARS-CoV-2) name was assigned by the International Committee on Taxonomy of Viruses(ICTV) [12, 13]. The phylogenetic clustered analysis from more than 30,000 genome sequence data submitted to GISAID database discloses that the virus belongs to the $\beta$-coronavirus family with a circular structure of 80-120 nm of diameter encapsulating a (+) ssRNA $[14,15]$. Due to the turbulent breakout of the infection outside the China, WHO declared SARS-CoV-2 caused COVID-19 to be a global pandemic on 11th March 2020, sparking intense global research initiatives to control or eliminate the virus and stop its further spread. The globally reported number of COVID-19 cases so far is 163 million with 3,373,080 deaths and 140 million recovered patients on 15th of May 2021. This review sheds light on the occurrence and transmission; clinical symptoms; molecular organisation and host cell interactions of the SARS-CoV-2 virus and discusses the current as well as future strategies to mitigate the COVID-19 pandemic. The presence of a global surveillance strategy for potential viral pandemics is of paramount importance after this pandemic.

\section{Geographical occurrence and its transmission}

Although the exact origin of the virus and whether it was created on purpose remains open to investigations and debates, the first publicized outbreak in human populations was at the Hunan seafood market at Wuhan city of China in late 2019 with confirmed zoonotic mode of transmission suspected to be from either/both bats and pangolins [16]. Authors have flagged the multi-species host trail that led to the outbreak in China [17]. However, clear answers are yet to emerge with some authors expressing serious concerns regarding a synthetic origin of coronavirus for the gain-offunction experimental study in the virus $[18,19]$.

\section{Clinical symptoms during COVID-19}

The high $(80 \%)$ genome similarity between SARS-CoV \& MERS-CoV is being speculated to be the cause of similar symptoms to MERS. The symptoms varies among the population ranging from common cold and flu like symptoms to mild pneumonia like symptoms in certain cases $[20,21]$. An interesting outcome of surveillance studies has been identification and testing of patient who don't show any known clinical symptoms and are called "asymptomatic". Even with positive RT-PCR tests and other clinical test data [22, 23], such individuals show no signs like cough, fever etc. Recently, WHO has categorically stated that asymptomatic individuals are much less likely to transmit COVID as compared to symptomatic individuals based on available data from various member nations. (https://www.who.int/emergencies/diseases/novel-cor onavirus-2019 accessed on 15th May 2021). A research finding among COVID-19 patient population the Chinese CDC reported that $80 \%$ of the cases are mild, $15 \%$ cases show severe symptoms and in $5 \%$ cases fall under critical hospitalized condition [24].

The WHO guidelines clearly state that SARS-CoV-2 infection may differ from person to person depending on various factors. After the viral infection the virus incubates in the upper respiratory tract of the human for 2-5 days and may take 2-14 days to develop the clinical symptoms in the individual starting from the mild symptoms of dry cough and throat pain $[25,26]$. Then after the increase of sufficient viral load in the patient the symptoms like muscle strain, nausea, loss of olfaction and taste in food, moderate fever $\left(99^{\circ} \mathrm{C}-103{ }^{\circ} \mathrm{C}\right)$ and diarrhoea [27]. On the 5th day the patient may feel difficulty in the breathing or any other symptoms depending upon the chronic disease history of the patient. On 7th day certain patients need hospitalization due to breathing issues and low oxygen saturation in body [28]. If patient does not stabilise after the medication, then 
on 10th day there may be a chance of develop the acute respiratory distress syndrome(ARDS) and due to the inflamed alveolar epithelium, edema occurs leading to critical case of pneumonia [29]. As per disease progression, an ICU setting may be required by the patient [30]. But as per current available data, 2-3\% mortality rate was reported with $>97 \%$ patients recovering from this extreme condition on or after 17th day of infection [31].

Similar conditions like high altitude pulmonary edema (HAPE) and bacterial pneumonia have been linked with COVID-19 owing to analogous symptoms. HAPE is a noncardiogenic disease that starts with labored breathing and vasoconstriction of pulmonary vasculature leading to lung edema. The low partial pressure of air at altitude leads to a ventilation-perfusion mismatch in the alveoli and this causes flooding of the alveoli with exudate rich in inflammatory proteins, resulting in pulmonary edema $[32,33]$. Although the modes of pathogenesis are completely different, there are a few analogous clinical symptoms, especially labored breathing and decreased lung function [34, 35]. A list is provided for the benefit of readers (Table 1) which summarizes the difference between HAPE and COVID-19 lung injury [36]. As is evident, even though some symptoms may be similar, both diseases mustn't be equated in terms of treatment modalities and therapeutic solutions. With bacterial pneumonia,

Table 1 Difference between HAPE and COVID-19 lung injury

\begin{tabular}{|c|c|}
\hline HAPE & COVID-19 \\
\hline Hypoxia causative & $\begin{array}{l}\text { Hypoxemia secondary to } \\
\text { respiratory failure }\end{array}$ \\
\hline No infectious agent & Transmitted viral disease \\
\hline $\begin{array}{l}\text { Hypoxia-induced } \\
\text { pulmonary hypertension }\end{array}$ & $\begin{array}{l}\text { Pulmonary hypertension due } \\
\text { to multiple causes }\end{array}$ \\
\hline $\begin{array}{l}\text { Inflammatory factors } \\
\text { secondary }\end{array}$ & $\begin{array}{l}\text { Primary alveolar-interstitial } \\
\text { Inflammation; } \\
\text { intense host-cytokine mediated response }\end{array}$ \\
\hline $\begin{array}{l}\text { Reversible with } \\
\text { supplemental oxygen }\end{array}$ & $\begin{array}{l}\text { Not reversible with oxygen } \\
\text { Alone }\end{array}$ \\
\hline Affects only the lung & $\begin{array}{l}\text { Affects lung, kidney, heart, } \\
\text { and nervous system }\end{array}$ \\
\hline $\begin{array}{l}\text { No multi-organ system } \\
\text { Failure }\end{array}$ & $\begin{array}{l}\text { Deaths from multi-organ } \\
\text { system failure }\end{array}$ \\
\hline $\begin{array}{l}\text { Rarely pre-existing } \\
\text { conditions worsen } \\
\text { outcome }\end{array}$ & $\begin{array}{l}\text { Common pre-existing } \\
\text { conditions worsen outcome }\end{array}$ \\
\hline Genetic susceptibility & Possible genetic susceptibility \\
\hline Age independent & $\begin{array}{l}\text { Increased mortality with } \\
\text { increased age }\end{array}$ \\
\hline
\end{tabular}

the infectious agent is a bacteria and mode of treatment is quite different.

\section{Genome and proteome organisation of SARS- Cov-2}

SARS-CoV 2 belongs to the of $\beta$-coronavirus family. The genome sequence data obtained from the patients of Wuhan showed more than $80 \%$ similarity between SARS$\mathrm{CoV}$ and MERS-CoV. The $30 \mathrm{~kb}$ genome of this SARSCoV-2 contains 29,891 nucleotides which can be found to encode 9860 amino acids upon its expression without any frameshifts and mutations $[37,38]$. The genetic material of this virus consists of the right-handed coiled, +-sense RNA with 5'capped region and 3'polyadenylated region. The genome of the virus comprises of 12 open reading frames (ORFs), 9 conserved leader sequences, 9 transcription regulatory sequences and 2 untranslated regions at the terminals $[39,40]$.

Within the viral genome, the first two ORFs named as ORF1a and ORF1b consists about two-third of the genome sequence and code 16 non-structural proteins (nsps 1-16). The ORF1a region codes cysteine proteases known as papain-like protease $(4955-5900 \mathrm{~kb})$ and 3CL-main protease(10555-10977 kb) from the nsp-3 and nsp-5 regions, respectively. The ORF-1b region codes the replicase (13442-16236 kb), helicase(16237-18043 kb) and endoribonuclease $(19,621-20,658 \mathrm{~kb})$ from the nsp-12, nsp-13 and nsp-15, respectively. The remaining one-third portion of the genome comprises of four ORFs which code the four structural proteins: spike (S), membrane (M), envelope (E) and nucleocapsid (N) proteins as well as accessory proteins that help evade host immune response [41, 42] (Fig. 1).

The protease enzyme plays a very crucial role in the replication process by maintaining the genome organisation of the non-structural proteins of COVID-19. The $\mathrm{N}$-terminal of the polyprotein is cleaved by the Papain-like protease to form nsp- 1, 2 and 3. Likewise the C-terminal of the polyprotein is cleaved by the 3CL-protease at 11 different sites of the P1 region and facilitates the release of the non-structural proteins [43, 44]. The helicase enzyme of the CoV-2 is mainly responsible for the hydrolysis of Nucleoside-triphosphates (NTPs) and promotes the unwinding of the viral RNA during its replication inside host cell. Endoribonuclease enzyme is one of the important enzymes among the coronavirus family as it can supress the INF- $\gamma$ response in the alveolar macrophages. The spike protein of the SARS-CoV-2 is a clove shaped trimeric Type-I transmembrane protein and contains three regions: ectodomain, intracellular domain and transmembrane domain. Crystallographic investigations reveal the 

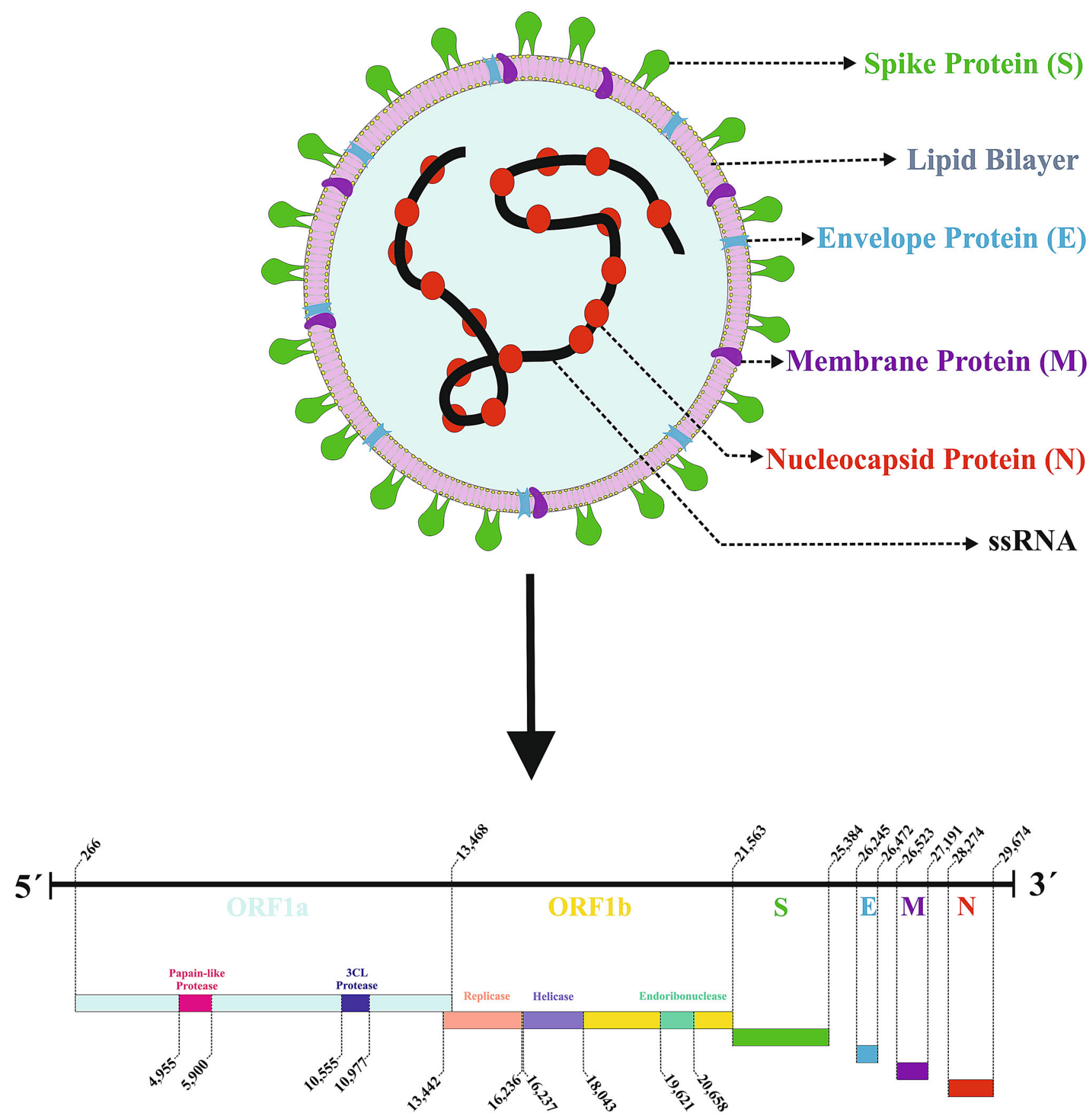

Fig. 1 Shows the schematic structure of a typical SARS-CoV-2 with all its components and the magnified image of its single stranded viral RNA with the arrangements of different coding genes

ectodomain to consist of S1 and S2 as two receptor binding domain(RBD), helping viral particle enter into the host cell $[45,46]$. Envelope protein found in coronavirus varies with a size of $8-12 \mathrm{kDa}$ and is the smallest transmembrane protein among the structural proteins which consists of a hydrophobic head region and a cytoplasmic tail region. The Envelope protein facilitates viral morphogenesis[47]. The membrane protein contains a long C-terminal and short
$\mathrm{N}$-terminal and interacts with the various proteins for maintaining the intracellular homeostasis in the virion. The nucleocapsid protein of SARS-CoV-2 consists of the $\mathrm{N}$-terminal domain(NTD) and C-terminal domain(CTD) which inhibits the cytokinesis process during cell division hence inhibits cell proliferation in humans [43]. 


\section{Entry and lifecycle of SARS-Cov-2 inside host cell}

All the coronaviruses show a common mode of entry into host cells. SARS-CoV-2 virus binds, via its membrane spike glycoprotein, to the Angiotensin Converting Enzyme 2(ACE2) and transmembrane protein serine protease 2(TMPRSS2) receptors present on the host cell surface. The expression of the ACE2 and TMPRSS2 receptors of the epithelial cells in various cell types of the host facilitate the binding with the spike protein of the virus [48]. The ACE2 attaches to the S1 subunit by its RBD and cleavage of both S1 and S2 subunit occurs at the cell membrane through endosomes of the host cell. The ability of virus to gain entry depends upon the availability of TMPRSS2 on host cell surface and its cleavage along with the furin activation. Afterwards, the formation of endosomal vesicle drives the entire virus into the cell through endosomal pathway [49]. The SARS-Cov-2 releases its (+ ve) sense RNA into the cell, the ORFs translate to form polyprotein1a and 1ab from the viral genome. The proteolysis of these polyproteins helps in the synthesis of non-structural proteins which forms the replication transcription complex (RTC)at the rough endoplasmic reticulum (RER). The synthesis of (-ve) sense RNA takes place at the RTC and acts as a template for the $(+\mathrm{ve})$ sense viral RNA inside the host cell. Due to the result of discontinuous transcription it synthesises multiple copies of sub-genomic mRNAs which translates into the viral proteins. These viral proteins along with the $(+\mathrm{ve})$ sense RNA enter into the endoplasmic reticulum (ER) and Golgi complex for their assembly into a new virion. The completed virion is transported via vesicles and released into the extracellular space. Surreptitiously, the viral load increases inside the host and causes infection [50, 51] (Fig. 2)

\section{Viral Pathogenesis and its impact on host immunity}

The SARS-CoV-2pathogenesis and infection in individuals depends upon various factors i.e. age, immunity, degree of lung function, lifestyle habits like smoking and drinking, exposure to the containment area and time of exposure etc. Viral entry into the host cell induces an acute immune inflammatory reaction and dysfunction of multiple ACE2 expressing tissues in organs like lungs, heart, liver, kidney, gastrointestinal tract along with the central nervous system and pulmonary vasculature of the host. This is referred to as cytokine storm [52, 53]. This dysfunction of the pulmonary endothelium leads to the generation of reactive oxygen species (ROS), sepsis, vascular thrombosis and abnormal coagulation of fluid tissue known as microvascular COVID-19 lung vessels obstructive thrombo-inflammatory syndrome (MicroCLOTS) [54]. The activated leukocytes produce Interleukin-6 (IL-6) along with various chemokines (i.e. CCL2, CCL3, CCL5, CXCL8, CXCL9, CXCL10 etc.) and cytokines such as IL$1 \beta$, IL-8, IL-12, IL-18, IL-33, monocyte chemo attractant protein 1 (MCP1), interferon- $\gamma$ inducible protein 10 (IP10 ), tumor necrosis factor $\alpha$ (TNF- $\alpha$ ), tumor growth factor $\beta$ (TGF- $\beta$ ) and macrophage inflammatory protein 1 A(MIP1A) [55]. IL-6 impacts thermoregulation, inflammation, cardiovascular health, cancer signalling, autoimmunity, central nervous system(CNS) function and bone density [56]. Cytokine levels become high during the systemic inflammatory response syndrome (SIRS) followed by fever and may lead to multi organ failure in some individuals. The recent findings show that Toll-like receptor(TLR) [57] binds to SARS-CoV-2 inducing the formation and release of pro-inflammatory cytokines like pro-IL-1 $\beta$ which further mature to form IL- $1 \beta$ causing lung inflammation and fibrosis.

\section{Development of different strategies to combat the outbreak}

The WHO declared this COVID-19 as a pandemic disease on 11th March 2020 and instructed the general population to undergo social distancing, self-isolation and practise extreme self-hygiene [58]. Apart from expanding the ambit of healthcare and research directed at the pandemic, the following specific measures have also been undertaken across the globe:

\section{Diagnosis}

The diagnosis of an infectious disease is essential to distinguish the infected from the healthy. Although myriad efforts are underway for improved diagnostics, two particular methods are being primarily used for their accuracy and efficiency.

\section{Molecular detection techniques}

Due to the open source release of genome sequence of this SARS-CoV-2 virus many government and private laboratories started RT-PCR based testing for COVID-19 in the preliminary stages. Different regions(i.e. ORF1B, ORF8, S, $\mathrm{N}, \mathrm{E}$ and $\mathrm{M}$ ) of the SARS-CoV-2 genome have been targeted using this detection method [59]. Although the main stay is the upper respiratory tract swab samples, newer methods exploiting various fluids and secretions like saliva, serum, ocular secretions, stool and urine samples are being developed. During RT-PCR, cDNA is synthesized from the 


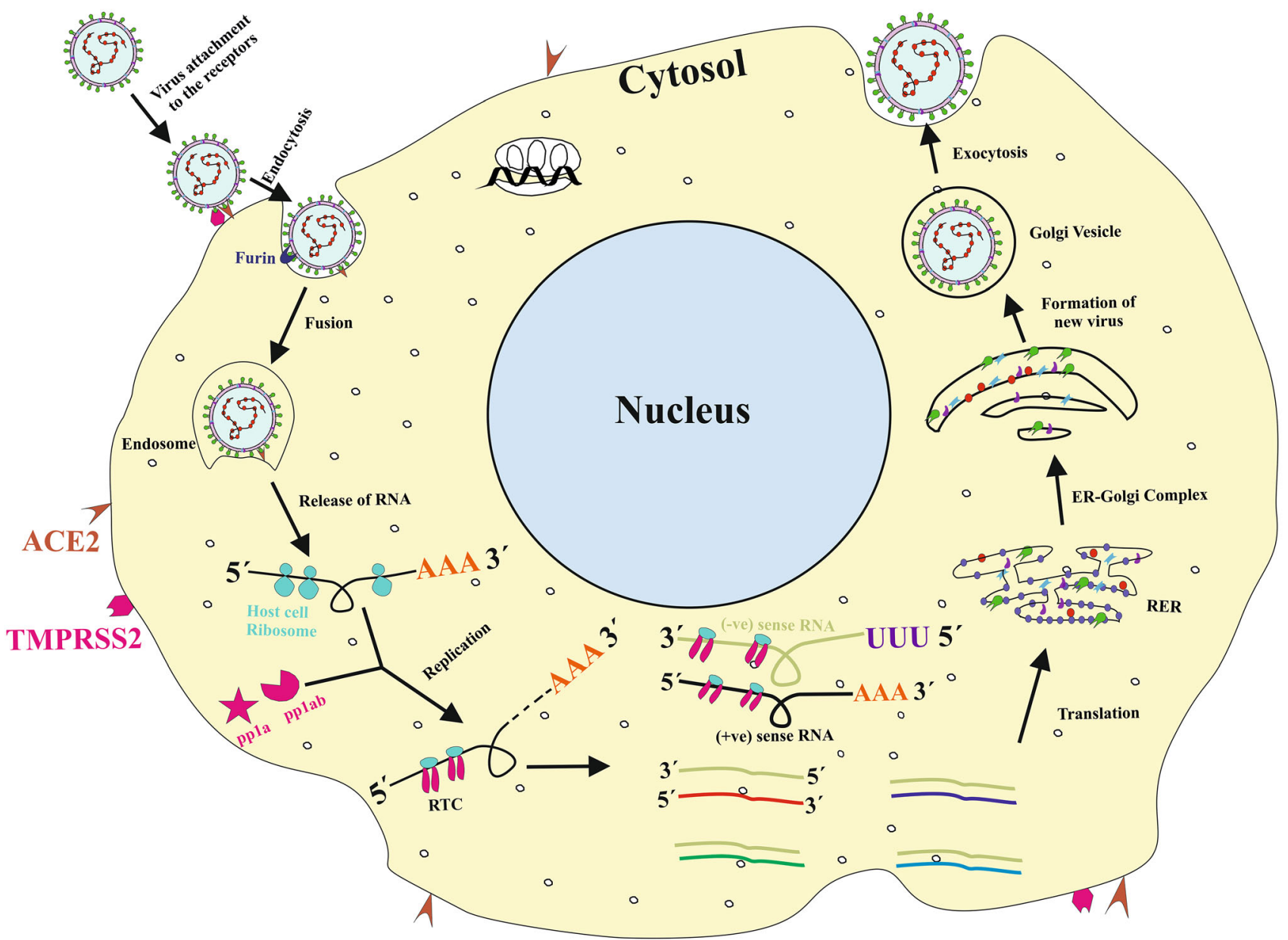

Fig. 2 Shows the structure of a typical mammalian cell with the attachment, entry and lifecycle of the SARS-CoV-2 and release of the new virion after replication.

viral RNA by the reverse transcription method, amplified and then labelled using florescent probe. The amplification and detection of the cDNA has been observed up to 40 cycles in a real-time manner [60].

Although RT-PCR has multiplexing and high-throughput platforms, new age technologies with greater cost-effectiveness, robustness, precision and time-efficient processing are being modulated towards a COVID testing platform including isothermal nucleic acid amplification, CRISPR based assay [61, 62], microarray, metagenomics sequencing [63].

\section{Immunological techniques}

Due to multi-reagent, instrument-sensitive, laborious and time-intensive nature of RT-PCR, large sample sizes (in population dense countries like India) routinely encountered during surveillance testing require an alternative testing method. Hence the immunological assay is being used during serological surveys for COVID-19 detection.
This immunological assay is based on the presence of IgM \& IgG antibody in the individuals. IgM acts as an early stage indicator of COVID-19 and IgG serves as an indicator for current or past infection [64]. The immune techniques used for testing include enzyme-linked immunosorbent assay (ELISA), specific chemosensors, lateral flow immunochromatography and neutralization bioassay. Although less accurate, the rapid antibody test is time- and cost- efficient as compared to RT-PCR, particularly when dealing with large sample sizes.

\section{Strategic healthcare management during the pandemic}

The second most important factor for successfully eradicating an infectious disease after its diagnosis is therapeutic intervention to cure the infected. Currently, most of the focus is on developing vaccines and antiviral drugs specific 
to SARS-CoV-2. The sub-sections below highlight current efforts in this direction.

\section{Precaution}

The Centers for Disease Control and prevention (CDC) have issued the advisory for this COVID-19 pandemic to use the mask when you step out of home, a social distancing of six feet distance in the crowded locations and public places along with the regular hand washing with the help of hand wash and sanitizers approved by FDA. Different types of mask and the proper procedure of wearing and its disposal information can be found according to the CDC guidelines (https://www.cdc.gov/coronavirus/2019ncov/prevent-getting-sick/prevention.html). The government of every country with NGOs spreading the selfawareness among the people in different corners of earth with the help of media houses to control the disease at preliminary level $[65,66]$. A regular health monitoring and check-up is also recommended by the WHO in case someone feels unhealthy or any kind of discomfort.

\section{Vaccination}

Current efforts are focused on vaccine development against SARS-CoV-2 and its worldwide distribution. The traditional method of vaccine development involves attenuated pathogen or the pathogen's protein capsid being injected into the host and causing immune memory. But newer strategies involve creating mRNA vaccines that cause insertion of mRNA into host cells and an immune response without disease development [67, 68]. The latest information on the emergency approval and preventive measures on vaccination process can be accessed from the COVID19 data management organisations (https://vaccine.icmr. org.in/covid-19-vaccine) \& (https://www.cdc.gov/cor onavirus/2019-ncov/vaccines/index.html).

\section{Antiviral drugs therapy/drug repurposing}

The search for a drug that is specifically developed against SARS-CoV-2 is yet to be concluded. Although drugs like remdesivir have been found effective, they remain far from adequate[69, 70]. In addition, certain FDA approved drugs like Favipiravir, Arbidol, hydroxychloroquine, Nafamostat, Baricitiniv, Rivavirin and Lopinavir are used in critical COVID-19 patients as per physicians' advice with selfdeclaration [71]. Nano-drug delivery machines are also a hope for COVID-19 cure in the near future [72, 73]. The practice of drug-repurposing has also suddenly come in the limelight. Completely unrelated drugs, originally developed for purposes not even remotely close to curing viral diseases have been found effective against SARS-CoV-2, namely, dexamethasone [74] and ivermectin [75, 76]. Such drugs have a proven safety and efficacy profile and readily available manufacturing capacity.

\section{Oxygen therapy}

The oxygen as a supplement can be beneficial in the COVID-19 patients as it can regulate the autoimmunity, replication in virus infected cells and supresses the expression of ACE2 in the host cells. But the $\mathrm{SpO}_{2}$ level shouldn't increase above $96 \%$ as it may affect the HIF-1 $\alpha$ expression and suppression of glycolysis in the patients showing ARDS. One of the major reasons of mortality in COVID-19 is rapid decreases in $\mathrm{SpO}_{2}$ levels of some patients. Hence the patient experiences issues in breathing and requires oxygen mask, respiratory catheter and lastly mechanical ventilator for respiration [77, 78].

\section{Plasma therapy}

Also called convalescent plasma therapy, it's an experimental therapy on COVID-19 patients who show ARDS symptom and do not respond to drug treatment. This method has been approved by U.S. food and drug administration (FDA) authority only for an emergency use and is limited to critically affected patients. The necessity and use of therapeutic approach is mainly decided by a committee of expert physicians by observation of patient's clinical history and under critical monitoring [79]. In this method the plasma is collected from a healthy recovered patient from COVID-19 and given to the patients in the ICUs [80]. It is recommended on a case-by-case basis due to the risk of transfer of other pathogens like HIV, Hepatitis virus (B, $\mathrm{C}$ ), other infections and allergic reactions. Plasma therapy helps in recovery of the patients when no alternative treatments are available [81, 82].

\section{Future perspective}

Understanding of COVID-19 as a disease is still in its infancy with more questions yet to be even realized. Interesting snippets like associations between ABO blood group showing A blood group as more prone to COVID-19 [83]; and reactive oxygen species (ROS) and COVID-19 inflammation [84] may lead to further greater findings helping us eradicate COVID-19 and other flu like diseases.

Assuming the reader has read the abovementioned resources, it is imperative that modern genomics, proteomics and bioinformatics based studies of infected patients be undertaken but only after the basic molecular mechanisms are clarified using cell culture investigations. In case the pandemic expands aggressively, we must 
investigate the biofluid proteomes of the infected patients using proteomics approach. However, a more targeted approach is recommended [85]. Targeted proteomics is a much better option regarding an infectious disease instead of broad-spectrum whole proteome studies without a sound molecular basis. Even if a broad-spectrum proteome wide analysis of COVID patients' blood/saliva/other biofluids/ tissues is undertaken at this stage, extensive access to high throughput technical facilities like LC-MS/MS, RNA-seq and NMR at BSL-3 level is highly necessary to elucidate the molecular basis of disease. The machine learning approaches for the analysis of the data in association with the computer aided drug design tools and techniques can be a great aid for the data analysis and interpretation. The validation of the computational approach by means of different experimental procedures is highly essential. Large scale sample collection should be continued to help in the molecular endeavour. Simultaneous efforts for better diagnostics and immediate drug manufacturing and distribution should also hold the pandemic at manageable levels till further success is achieved. An important point to note in the current pandemic was the absence of any specific agency designed to survey viral/microbial strains with epidemic/pandemic potential in humans and provide early information in the months of November/December 2019 during the first cases of COVID-19. This emphasizes the need for a robust, coordinated global surveillance strategy that is directed at early identification of infectious agents like viruses and mass engagement to help communities prepare at multiple levels so that epidemic/pandemic(s) are prevented before assuming unmanageable proportions.

\section{Conclusions}

This review summarizes the key information about SARS$\mathrm{CoV}-2$ infection, its molecular structure, its replication and spread of disease as well as the strategies to combat its spread. We find that SARS-CoV-2 virus requires a lot of further study regarding the exact orchestration of its evasion of host immune system, its method of entry into host cell, its ability to cause inflammation, its ability to hijack cellular machinery and its ability to cut across host species. Once we have made significant strides in these areas, much can be done in the development of therapeutic molecules directed against the virus. Further studies should be directed at these aspects to formulate better treatment strategies against SARS-CoV-2. Till then, scientifically issued preventive measures like social distancing, sanitization, personal hygiene, using face shields and masks and practising self-isolation must become a daily routine for all.
Acknowledgements SM is a recipient of DRDO-JRF fellowship. SP is a recipient of CSIR-SRF fellowship. We are acknowledging CorelDRAW ${ }^{\circledR}$ X8 Graphics Suite software package for the non-commercial education license which is being used for the illustration of the figures.

Authors contribution YA conceptualized the manuscript. SM wrote the manuscript and designed the figures for convenient representation. YA and SP delineated the table and critically evaluated the manuscript.

Funding Authors have not received any special funding for this work.

Availability of data and materials The figures and table are not adopted from any sources so Not applicable.

Code Availability Not applicable.

\section{Declarations}

Conflict of interest Authors state no conflict of interests.

Consent for Publication All authors agreed.

\section{References}

1. van Regenmortel MHV, Mahy BWJ. Desk encyclopedia of general virology. 1st ed. Elsevier; 2010.

2. Kotterman MA, Chalberg TW, Schaffer DV. Viral vectors for gene therapy: translational and clinical outlook. Annu Rev Biomed Eng. 2015;17:63-89.

3. Woolhouse M, et al. Human viruses: discovery and emergence. Philos Trans R Soc Lond B Biol Sci. 2012;367(1604):2864-71.

4. Lim ES, et al. Early life dynamics of the human gut virome and bacterial microbiome in infants. Nat Med. 2015;21(10):1228.

5. Adams MJ, et al. Recently agreed changes to the International Code of Virus Classification and Nomenclature. Arch Virol. 2013;158(12):2633-9.

6. King AMQ, et al. Virus taxonomy: ninth report on the International Committee on Taxonomy of Viruses. Elsevier; 2011.

7. Abdel-Moneim AS, Abdelwhab EMJP. Evidence for SARS-CoV2 infection of animal hosts. Pathogen. 2020;9(7):529.

8. Huang W-H, et al. novel coronavirus disease (COVID-19) in Taiwan: Reports of two cases from Wuhan. China. J Microbiol Immunol Infect. 2020;53(3):481-4.

9. Wei X-S, et al. A cluster of health care workers with COVID-19 pneumonia caused by SARS-CoV-2. J Microbiol Immunol Infect. 2020;54:54-60.

10. Tian $\mathrm{H}$, et al. An investigation of transmission control measures during the first 50 days of the COVID-19 epidemic in China. Science. 2020;368(6491):638-42.

11. Tan W, et al. A novel coronavirus genome identified in a cluster of pneumonia cases-Wuhan, China 2019-2020. China CDC Weekly. 2020;2(4):61-2.

12. Chen Y, Liu Q, Guo DJJ. Emerging coronaviruses: genome structure, replication, and pathogenesis. J Med Virol. 2020;92(4):418-23.

13. Wang L-S, et al. A review of the 2019 Novel Coronavirus (COVID-19) based on current evidence. Int J Antimicrob Agents. 2020;53:105948. 
14. Nadjib BMJJPCT. Effective antiviral activity of essential oils and their characteristic terpenes against coronaviruses: an update. Journal of Pharmacology \& Clinical Toxicology. 2020;8(1):1138.

15. Nakagawa S. Miyazawa, and regeneration, Genome evolution of SARS-CoV-2 and its virological characteristics. Inflamm Regener. 2020;40(1):1-7.

16. Varsha B, et al. Coronavirus-A Deadly Outbreak in Wuhan Province of People Republic China. Biosci Biotech Res Asia. 2020;17(1):01-5.

17. Liu Z, et al. Composition and divergence of coronavirus spike proteins and host ACE2 receptors predict potential intermediate hosts of SARS-CoV-2. J Med Virol. 2020;92(6):595-601.

18. Rasmussen AL. On the origins of SARS-CoV-2. Nat Med. 2021;27(1):9-9.

19. Okediya $\mathrm{P}$, China coronavirus bioweapon conspiracy theory: The application of international humanitarian law by states. SSRN J. 2020.

20. Wu A, et al. Genome composition and divergence of the novel coronavirus (2019-nCoV) originating in China. Cell Host Microbe. 2020;27:325.

21. Sen S, et al. Coronaviruses: origin and evolution. Lancet Infect Dis. 2020;76(2):136-41.

22. Pan $X$, et al. Asymptomatic cases in a family cluster with SARSCoV-2 infection. Lancet Infect Dis. 2020;20(4):410-1.

23. Long Q-X, et al. Clinical and immunological assessment of asymptomatic SARS-CoV-2 infections. 2020: p. 1-5.

24. Wang W, et al. Detection of SARS-CoV-2 in different types of clinical specimens. JAMA. 2020;323(18):1843-4.

25. Castagnoli R, et al. Severe acute respiratory syndrome coronavirus 2 (SARS-CoV-2) infection in children and adolescents: a systematic review. JAMA Pediatr. 2020;174:882.

26. Favre $\mathrm{G}$, et al. Guidelines for pregnant women with suspected SARS-CoV-2 infection. Lancet Infect Dis. 2020;20(6):652-3.

27. Pan Y, et al. Viral load of SARS-CoV-2 in clinical samples. Lancet Infect Dis. 2020;20(4):411-2.

28. Halpin DM, et al. Do chronic respiratory diseases or their treatment affect the risk of SARS-CoV-2 infection? Lancet Infect Dis. 2020;8(5):436-8.

29. Helms J, et al. High risk of thrombosis in patients with severe SARS-CoV-2 infection: a multicenter prospective cohort study. 2020;46:p. 1-10.

30. Simonnet A, et al. High prevalence of obesity in severe acute respiratory syndrome coronavirus-2 (SARS-CoV-2) requiring invasive mechanical ventilation. 2020;28(7):1195-1199.

31. Lai C-C, et al. Severe acute respiratory syndrome coronavirus 2 (SARS-CoV-2) and corona virus disease-2019 (COVID-19): the epidemic and the challenges. Int $\mathbf{J}$ Antimicrob Agents. 2020;55:105924.

32. Betz T, et al. Does high alveolar fluid reabsorption prevent HAPE in individuals with exaggerated pulmonary hypertension in hypoxia? High Alt Med Biol. 2015;16(4):283-9.

33. Paul S, Bhargava K, Y.J.P.C.A, . Ahmad, The meta-analytical paradigm in an in silico hybrid: Pathways and networks perturbed during exposure to varying degrees of hypobaric hypoxia. Proteomics Clin Appl. 2017;11(7-8):1600160.

34. Archer SL, Sharp WW, Weir EKJC. Differentiating COVID-19 pneumonia from acute respiratory distress syndrome (ARDS) and high altitude pulmonary edema (HAPE): Therapeutic Implications. Circulation. 2020;142:101.

35. Coen M, et al. Hypoxemia in COVID-19; Comment on: "The neuroinvasive potential of SARS-CoV2 may play a role in the respiratory failure of COVID-19 patients. J Med Virol. 2020;92:1705.

36. Luks AM, et al. COVID-19 lung injury is not high altitude pulmonary edema. High Alt Med Biol. 2020;21(2):192-3.
37. Coppola M, Mondola R. Phytotherapeutics and SARS-CoV-2 infection: Potential role of bioflavonoids. Med Hypotheses. 2020;140:109766.

38. Zhou Y, et al. Network-based drug repurposing for novel coronavirus 2019-nCoV/SARS-CoV-2. Cell Discovery. 2020;6(1):1-18.

39. Kim D, et al. The architecture of SARS-CoV-2 transcriptome. 2020;181(4):914-921.

40. Banu S, et al. A distinct phylogenetic cluster of Indian SARSCoV-2 isolates. 2020;7(11).

41. Rockett RJ, et al. Revealing COVID-19 transmission in Australia by SARS-CoV-2 genome sequencing and agent-based modeling. 2020:1-7.

42. Koulgi S, et al. Drug repurposing studies targeting SARS-CoV-2: an ensemble docking approach on drug target 3C-like protease (3CLpro). J Biomol Struct Dyn. 2020;179:1-21.

43. Shang J, et al. Structural basis of receptor recognition by SARSCoV-2. Travel Med Infect Dis. 2020;581(7807):221-4.

44. Hall DC, Ji HF. A search for medications to treat COVID-19 via in silico molecular docking models of the SARS-CoV-2 spike glycoprotein and 3CL protease. Trav Med Infect Dis. 2020;35:101646.

45. Andersen KG, et al. The proximal origin of SARS-CoV-2. Nature Medcine. 2020;26(4):450-2.

46. Senapati $S$, et al. A pilot study to investigate the fecal dissemination of SARS-CoV-2 virus genome in COVID-19 patients in Odisha, India. 2020.

47. Grifoni A, et al. A sequence homology and bioinformatic approach can predict candidate targets for immune responses to SARS-CoV-2. Cell Host Microbe. 2020;27:671.

48. Lukassen S, et al. SARS-CoV-2 receptor ACE 2 and TMPRSS 2 are primarily expressed in bronchial transient secretory cells. EMBO J. 2020;39(10):e105114.

49. Ma D, et al. Expression of SARS-CoV-2 receptor ACE2 and TMPRSS2 in human primary conjunctival and pterygium cell lines and in mouse cornea. Eye. 2020;34:1-8.

50. Zhang $\mathrm{H}$, et al. Angiotensin-converting enzyme 2 (ACE2) as a SARS-CoV-2 receptor: molecular mechanisms and potential therapeutic target. Intensive Care Med. 2020;46(4):586-90.

51. Lamers MM, et al. SARS-CoV-2 productively infects human gut enterocytes. 2020;369(6499):50-54.

52. Robba C, et al. Multiple organ dysfunction in SARS-CoV-2: MODS-CoV-2. New York: Taylor \& Francis; 2020.

53. Pedersen SF, Ho Y-CJTJ. SARS-CoV-2: a storm is raging. J Clin Investig. 2020;130(5):2202.

54. Colantuoni A, et al. COVID-19 Sepsis and Microcirculation Dysfunction. Front Physiol. 2020;11:747.

55. Coperchini F, et al. The cytokine storm in COVID-19: an overview of the involvement of the chemokine/chemokine-receptor system. Cytokine Growth Factor Rev. 2020;53:25.

56. Nikolich-Zugich J, et al. SARS-CoV-2 and COVID-19 in older adults: what we may expect regarding pathogenesis, immune responses, and outcomes. GeroScience. 2020;42:1-10.

57. Chen W-H, et al. The SARS-CoV-2 vaccine pipeline: an overview. Current Tropical Medicine Reports. 2020;7:1-4.

58. Bedford J, et al. COVID-19: towards controlling of a pandemic. The Lancet. 2020;395(10229):1015-8.

59. Tahamtan A, Ardebili A. Real-time RT-PCR in COVID-19 detection: issues affecting the results. New York: Taylor \& Francis; 2020.

60. Ai $\mathrm{T}$, et al. Correlation of chest $\mathrm{CT}$ and RT-PCR testing in coronavirus disease 2019 (COVID-19) in China: a report of 1014 cases. Radiology. 2020;296:200642.

61. Broughton JP, et al. CRISPR-Cas12-based detection of SARSCoV-2. Nat Biotechnol. 2020;38:1-5. 
62. Mohanty S, Dash A, Pradhan CKJ. CRISPR-Cas9 Technology: A magical tool for DNA editing. Cellular Physiology. 2019;1(1):1-11.

63. Carter LJ, et al. Assay techniques and test development for COVID-19 diagnosis. Washington: ACS Publications; 2020.

64. Li Z, et al. Development and clinical application of a rapid IgMIgG combined antibody test for SARS-CoV-2 infection diagnosis. J Med Virol. 2020;9:1518.

65. Latkin CA, et al. Mask usage, social distancing, racial, and gender correlates of COVID-19 vaccine intentions among adults in the US. PLoS ONE. 2021;16(2):e0246970.

66. Sun CX, et al. Public Awareness and Mask Usage during the COVID-19 Epidemic: A Survey by China CDC New Media. Biomed Environ Sci. 2020;33(8):639-45.

67. Prompetchara E, et al. Immune responses in COVID-19 and potential vaccines: Lessons learned from SARS and MERS epidemic. 2020;38(1):1-9.

68. Rostad CA, E.J.D,. Anderson, Optimism and caution for an inactivated COVID-19 vaccine. Lancet Infect Dis. 2021;5:581.

69. McCreary EK, Angus DC. Efficacy of Remdesivir in COVID-19. JAMA. 2020;324:1041.

70. Beigel HJ, et al. Remdesivir for the Treatment of Covid-19Preliminary Report. New Engl J Med. 2020;383:1813-26.

71. Hafeez A, et al. A Review of COVID-19 (Coronavirus Disease2019) Diagnosis, Treatments and Prevention. 2019;4(2):116-125.

72. Hu TY, Frieman M, Wolfram JJNN. Insights from nanomedicine into chloroquine efficacy against COVID-19. Nat Nanotechnol. 2020;15(4):247-9.

73. Priyadarsini $\mathrm{S}$, et al. Graphene and graphene oxide as nanomaterials for medicine and biology application. 2018;8(2):123-37.

74. Cain DW, Cidlowski JA. After 62 years of regulating immunity, dexamethasone meets COVID-19. Nat Rev Immunol. 2020;20:587.
75. Gupta D, Sahoo AK, Singh A. Ivermectin: potential candidate for the treatment of Covid 19. Braz J Infect Dis. 2020;24:369.

76. Chaccour C, et al. Ivermectin and COVID-19: Keeping Rigor in Times of Urgency. Am J Trop Med Hyg. 2020;102(6):1156-7.

77. Gattinoni L, et al. COVID-19 pneumonia: different respiratory treatments for different phenotypes? Berlin: Springer; 2020.

78. Srinivasan S, Panigrahy AK. Official Publication of Indian Society of Critical Care Medicine, COVID-19 ARDS: Can Systemic Oxygenation Utilization Guide Oxygen Therapy? Indian J Crit Care Med. 2021;25(2):115.

79. Tanne JH. Covid-19: FDA approves use of convalescent plasma to treat critically ill patients. BMJ. 2020;368

80. Duan K, et al. The feasibility of convalescent plasma therapy in severe COVID-19 patients: a pilot study. medRxiv;2020.

81. Chen L, et al. Convalescent plasma as a potential therapy for COVID-19. Lancet Infect Dis. 2020;20(4):398-400.

82. Shen C, et al. Treatment of 5 critically ill patients with COVID19 with convalescent plasma. JAMA. 2020;323(16):1582-9.

83. Thomas $\mathrm{T}$, et al. Evidence for structural protein damage and membrane lipid remodeling in red blood cells from COVID-19 patients. 2020;11:4455-4469.

84. Teuwen L-A, et al. COVID-19: the vasculature unleashed. Nat Rev Immunol. 2020;20:1-3.

85. Shen B, et al. Proteomic and metabolomic characterization of COVID-19 patient sera. 2020;182(1):59-82.

Publisher's Note Springer Nature remains neutral with regard to jurisdictional claims in published maps and institutional affiliations. 